\title{
Baseline CD4 and mortality trends in the South African human immunodeficiency virus programme: Analysis of routine data
}

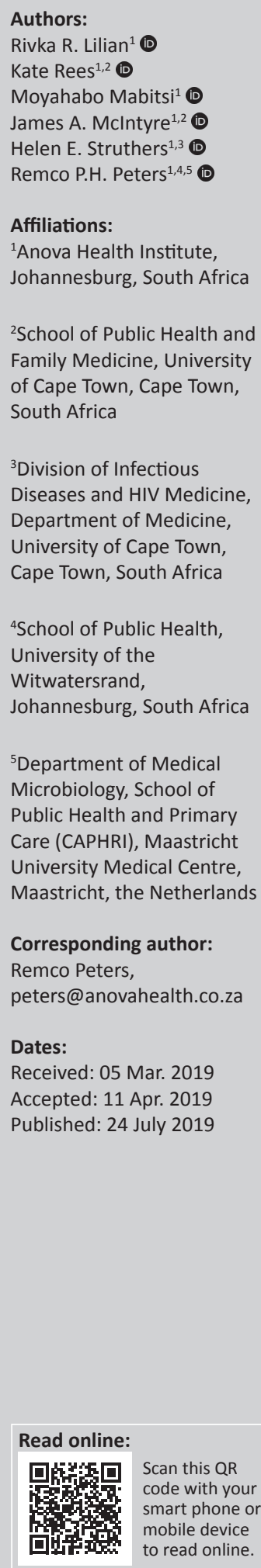

Background: Despite widespread availability of antiretroviral therapy (ART) in South Africa, there remains a considerable burden of human immunodeficiency virus (HIV)-related morbidity and mortality.

Objectives: To describe ART initiation and outcome trends over time, with a focus on clients presenting with advanced HIV-infection, so as to identify interventions to reduce morbidity and mortality.

Methods: Routine TIER.Net data from HIV-infected adults who had a documented baseline CD4 count and were newly initiating ART in Johannesburg or Mopani districts from 2004 to 2017 were analysed. Trends in baseline CD4 count and 5-year mortality were investigated and the population initiating ART with CD $<200$ cells $/ \mathrm{mm}^{3}$ was described.

Results: The Johannesburg and Mopani data sets comprised 203131 and 101814 records, respectively. Although median CD4 count increased over time, the proportion of initiations at CD4 < 200 cells $/ \mathrm{mm}^{3}$ in 2017 remained high (Johannesburg 39\%, Mopani 35\%). Mortality was significantly increased among clients with CD4 $<200$ compared to those with higher baseline counts $(p<0.001)$. Even though mortality among clients with low CD4 declined over time, likely because of improved drug regimens, in 2016-2017 mortality was still significantly increased among these clients $(p<0.001)$. Delivery of cotrimoxazole prophylaxis to clients with low CD4 declined over time to $<30 \%$ in 2017 and was associated with clinical stage. Presentation with CD $4<200$ cells $/ \mathrm{mm}^{3}$ was associated with older age, male gender and hospitalisation.

Conclusion: A concerningly large proportion of South Africans still initiate ART at low CD4 counts. This is associated with increased mortality and requires targeted interventions to improve delivery of prophylactic regimens and early engagement in care.

Keywords: TIER.Net; Antiretroviral Therapy; CD4; Mortality; HIV; South Africa.

\section{Introduction}

In 2017, there were 6.9 million adults living with human immunodeficiency virus (HIV) in South Africa, of whom $61 \%$ were receiving treatment. ${ }^{1}$ This equates to 4.2 million adults receiving antiretroviral therapy (ART), forming the largest treatment programme in the world. ${ }^{1}$ South Africa's ART programme has demonstrated successful initiation and management of clients on treatment for over a decade, despite rapid programmatic scale-up over this time, ${ }^{2}$ and has achieved near-normal life expectancy for HIV-infected adults with timely ART initiation. ${ }^{3}$ The ART programme is thus an essential component of the third Sustainable Development Goal which aims to ensure healthy lives and end the AIDS epidemic by $2030 .{ }^{4}$

South Africa's ART programme has evolved over time to accommodate increasing numbers of HIV-infected clients and to provide improved care and treatment services (Table 1). $5,6,7,8,9,10$ This has encompassed expansion of the ART eligibility criteria from clients with CD4 counts $<200$ cells $/ \mathrm{mm}^{3}$ in $2004^{5}$ to universal test and treat (UTT) in $2016,{ }^{8}$ as well as a shift from doctorto nurse-managed care and decentralisation of ART services from hospitals to primary healthcare sites. ${ }^{11}$ Across all years, cotrimoxazole preventive therapy (CPT) has been recommended for clients with baseline CD4 counts below 200 cells $/ \mathrm{mm}^{3}$ as a means of protecting against infections

How to cite this article: Lilian RR, Rees K, Mabitsi M, et al. Baseline CD4 and mortality trends in the South African human immunodeficiency virus programme: Analysis of routine data. S Afr J HIV Med. 2019;20(1), a963. https://doi.org/10.4102/sajhivmed.v20i1.963

Copyright: @ 2019. The Authors. Licensee: AOSIS. This work is licensed under the Creative Commons Attribution License. 
TABLE 1: South African guidelines for treatment of adults with human immunodeficiency virus infection.

\begin{tabular}{|c|c|c|c|c|c|}
\hline Variable & 2004 guidelines & April 2010 guidelines & March 2013 guidelines $\dagger$ & December 2014 guidelines & August 2016 circular $\S$ \\
\hline ART eligibility & $\begin{array}{l}\text { CD4 count }<200 \text { cells } / \mathrm{mm}^{3} \\
\text { or } \\
\text { WHO Stage IV disease }\end{array}$ & $\begin{array}{l}\text { CD4 count } \leq 200 \text { cells } / \mathrm{mm}^{3} \\
\text { or } \\
\text { CD4 count } \leq 350 \text { cells } / \mathrm{mm}^{3} \\
\text { in clients with TB/HIV or } \\
\text { pregnant women } \\
\text { or } \\
\text { WHO stage IV disease } \\
\text { or } \\
\text { MDR/XDR-TB }\end{array}$ & $\begin{array}{l}\text { CD4 count } \leq 350 \text { cells } / \mathrm{mm}^{3} \\
\text { or } \\
\text { WHO stage III or IV disease } \\
\text { or } \\
\text { Clients with all types of TB }\end{array}$ & $\begin{array}{l}\text { CD4 count } \leq 500 \text { cells } / \mathrm{mm}^{3} \\
\text { or } \\
\text { WHO stage III or IV disease } \\
\text { or } \\
\text { Active TB disease } \\
\text { or } \\
\text { Pregnant and breastfeeding } \\
\text { women } \\
\text { or } \\
\text { Known HBV co-infection }\end{array}$ & $\begin{array}{l}\text { UTT: all HIV-infected } \\
\text { clients regardless of } \\
\text { CD4 count }\end{array}$ \\
\hline First-line ART regimen (new clients) & $\mathrm{d} 4 \mathrm{~T}+3 \mathrm{TC}+\mathrm{EFV} / \mathrm{NVP}$ & $\mathrm{TDF}+3 \mathrm{TC} / \mathrm{FTC}+\mathrm{EFV} / \mathrm{NVP}$ & $\mathrm{FDC} \dagger \dagger$ & $\mathrm{FDC} \dagger \dagger$ & \\
\hline CPT & All clients initiating ART & $\begin{array}{l}\mathrm{CD} 4 \leq 200 \text { cells } / \mathrm{mm}^{3} \\
\text { WHO stage II, III or IV } \\
\text { disease (including TB) }\end{array}$ & & $\begin{array}{l}\text { CD4 count } \leq 200 \text { cells } / \mathrm{mm}^{3} \\
\text { WHO stage III or IV disease } \\
\text { HIV/TB co-infection }\end{array}$ & \\
\hline
\end{tabular}

Source: National Department of Health of South Africa $5,6,6,7,9$

3TC, lamivudine; ART, antiretroviral therapy; CPT, cotrimoxazole preventive therapy; d4T, stavudine; EFV, efavirenz; FDC, fixed-dose combination; FTC, emtricitabine; HIV, human immunodeficiency virus; HBV, hepatitis B; MDR/XDR-TB, multidrug-resistant or extensively drug-resistant tuberculosis; NVP, nevirapine; TB, tuberculosis; TDF, tenofovir disoproxil fumarate; UTT, universal test and treat; WHO, World Health Organization

$\dagger$, Implementation date $=01$ April 2013:

$\$$,Implementation date $=01$ January 2015

$\S$, Implementation date $=01$ September 2016;

9, Implementation of the CD4 count $\leq 350$ cell $/ \mathrm{mm}^{3}$ cut-off occurred in August 2011, prior to the publication of the 2013 guidelines ${ }^{10}$;

$\dagger$, FDC consists of TDF, FTC and EFV.

and thereby reducing morbidity and mortality. ${ }^{5,6,9}$ Tripletherapy antiretroviral drug regimens have also been updated over time, from combination single formulation regimens including stavudine in $2004^{5}$ and tenofovir in $2010^{6}$ to a fixeddose combination (FDC), a single tablet containing three antiretroviral drugs (tenofovir, emtricitabine and efavirenz), in 2013. ${ }^{7}$ As the ART programme has evolved and expanded, it has become increasingly important to have an effective monitoring system, and in 2010 the Department of Health adopted an electronic monitoring and evaluation tool known as TIER.Net, which was developed by the University of Cape Town's Centre for Infectious Disease Epidemiology and Research. ${ }^{12}$ TIER.Net is used operationally to monitor baseline clinical care and client outcomes over time, providing a rich source of cross-sectional and longitudinal routine ART data.

Despite the widespread availability of ART, there is still a considerable burden of HIV-related morbidity and mortality. In South Africa, HIV accounted for almost two-thirds of medical admissions at one hospital in 2012 and 2013,,$^{13}$ with no improvement in the number of deaths due to AIDS nationally from 2013 to 2017, ${ }^{14}$ and in West Africa, AIDS-defining conditions remained the primary cause of hospitalisation among HIV-infected adults years after the scale-up of ART services. ${ }^{15}$ High morbidity and mortality is specifically associated with late presentation for HIV care, as indicated by low baseline CD4 counts or advanced clinical stage., ${ }^{3,16,17,18}$ These poor outcomes potentially undermine the populationlevel impact of the ART programme, as ART coverage in individuals is known to impact HIV transmission, incidence and community viral load. ${ }^{19,20}$ Interventions to improve ART initiation, specifically among clients at risk of presenting late for HIV care, are therefore essential to improve both individualand programme-level outcomes. This study used operational programme data to describe ART initiation and outcome trends over time, with a focus on clients presenting late for care, so as to identify programmatic gaps that can guide interventions to reduce HIV-associated morbidity and mortality. Two districts were investigated as examples of the urban and rural HIV epidemics in South Africa, namely, Johannesburg and Mopani districts. Specifically, this study aims to use routine TIER.Net data from adult clients in an urban and rural district of South Africa to (1) describe ART programme growth and baseline CD4 count over time, (2) analyse 5-year mortality in the context of baseline CD4 count and (3) describe the population initiating ART at low CD4 counts $\left(<200\right.$ cells $\left./ \mathrm{mm}^{3}\right)$ in 2017 in order to identify priority groups at high risk of mortality for intervention.

\section{Methods Study population and data source}

Routinely collected data from adults initiating ART in two districts of South Africa, Johannesburg district in Gauteng province and Mopani district in Limpopo province, were analysed. Of the seven regions in Johannesburg, four $(C, D, E$ and $G$ ) were included in the analysis, as these regions have been supported by Anova Health Institute and routine data were therefore available for analysis. Johannesburg district has a population density of 3044 persons $/ \mathrm{km}^{2}$ and is relatively economically affluent, falling into socio-economic quintile $5 .{ }^{21}$ In contrast, Mopani district is sparsely populated and socio-economically deprived, having a population density of 56.9 persons $/ \mathrm{km}^{2}$ and a socio-economic quintile of $2 .^{21}$ Antenatal HIV prevalence, a proxy for overall population prevalence, is $29.6 \%$ and $24.5 \%$ in Johannesburg and Mopani districts, respectively. ${ }^{22}$ Both districts provide HIV care and treatment services, with $71.8 \%$ and $72.9 \%$ of adults diagnosed with HIV-infection being retained on ART at 12 months, respectively. ${ }^{21}$

In April 2018, data for Johannesburg and Mopani districts were extracted from TIER.Net. Records were included in the analysis from clients initiating ART between 2004 and 2017 (inclusive), where clients were 15-80 years of age, were newly initiating ART and had a baseline CD4 count on record. In order to exclude outlying CD4 counts that were likely data errors, records with baseline counts above 2000 cells $/ \mathrm{mm}^{3}$ were excluded. For the Kaplan-Meier analysis only, clients 
who were lost to follow-up (LTFU) or had transferred out of the ART programme were also excluded.

\section{Statistical analysis}

Descriptive statistics were used to explore trends in ART initiation and baseline CD4 counts over time. Kaplan-Meier survival analysis was used to estimate the probability of death over time in clients with low baseline CD4 counts $\left(<200\right.$ cells $\left./ \mathrm{mm}^{3}\right)$. Only clients known to have died and those active in care were included in the Kaplan-Meier analysis. Follow-up time, defined as the time between ART start and last ART visit, was censored at 5 years after ART initiation. Where clients died after the initiation visit (i.e. ART initiation date and last visit date were the same), a follow-up time of half a day (0.001 years) was assigned. Survival curves were compared using a Peto-Peto-Prentice test for equality of survivor functions, which is not affected by differences in censoring patterns across groups and is appropriate even when hazard functions are not proportional. ${ }^{23}$

To describe the population presenting late for HIV care in 2017 , clients with baseline CD 4 counts $<200$ cells $/ \mathrm{mm}^{3}$ were compared to those with CD4 counts $\geq 200$ cells $/ \mathrm{mm}^{3}$ using Mann-Whitney and chi-squared $\left(\chi^{2}\right)$ or Fisher's exact tests for continuous and categorical variables, respectively. Viral load suppression was calculated using the last viral load test on record for each client and was defined as a last viral load result $<1000$ copies $/ \mathrm{mL}$ as per South African guidelines, which use 1000 copies $/ \mathrm{mL}$ as the cut-off for virological failure. ${ }^{9}$ Delivery of CPT to clients presenting for HIV care with baseline CD4 counts $<200$ cells $/ \mathrm{mm}^{3}$ was compared between clients with advanced clinical disease (World Health Organization [WHO] stage III or IV disease) and clients with WHO stage I or II disease using 95\% confidence intervals over the last 5 years (2013-2017). Analyses were performed using Microsoft Excel 2010 and Stata version 14.2 (StataCorp LLC, College Station, TX, USA). A $p$-value of $<0.05$ was considered significant.

\section{Ethical consideration}

The study was approved by the University of the Witwatersrand's Medical Ethics Committee (M140461). Individual patient consent was not required as this study analysed anonymised TIER.Net data that were routinely collected at healthcare facilities for monitoring purposes. No data collection was performed for the purposes of this study. In addition, no patient files or electronic medical records were retrieved or accessed at any stage.

\section{Results \\ Description of study population}

The Johannesburg data set comprised 340023 records from adult clients aged 15-80 years initiating ART between 2004 and 2017. Records from 83677 (25\%) clients were excluded, as these individuals were not newly initiating ART. A further $53178(16 \%)$ records were excluded because of missing baseline CD4 counts. Among the remaining 203168 records, $37(<1 \%)$ had baseline CD4 counts above 2000 and thus were also excluded, leaving a Johannesburg data set of 203131 records for analysis. The initial Mopani data set comprised 159904 records from adults initiating ART between 2004 and 2017, of which 36553 (23\%) were excluded because of ART initiation in clients who were not treatment naïve and a further 21517 (13\%) were excluded because of missing baseline CD4 counts. Among the remaining 101834 records, 20 (<1\%) with baseline CD4 counts above 2000 were also excluded, leaving a Mopani data set of 101814 records for analysis.

\section{Antiretroviral therapy initiation and baseline CD4 counts over time}

The ART programmes in both Johannesburg and Mopani districts expanded rapidly over time (Figure 1). A total of 203131 adults were initiated on treatment in Johannesburg compared to 101814 in Mopani. The number of ART initiations increased steadily each year from 2004 to 2013, but began to decline in Johannesburg from 2016 and in Mopani from 2015. Across all years, the majority of clients in both districts were women, ranging from $63 \%$ to $66 \%$ in Johannesburg and $68 \%$ to $77 \%$ in Mopani. Median age at ART initiation ranged from 35 to 37 years in Johannesburg and from 36 to 39 years in Mopani.

The mean and median baseline CD4 counts increased from 2004 to 2017 in both Johannesburg and Mopani districts (Figure $2 \mathrm{a}$ and $\mathrm{b}$ ). The increase has been consistent in Johannesburg, but Mopani took a longer time to show this

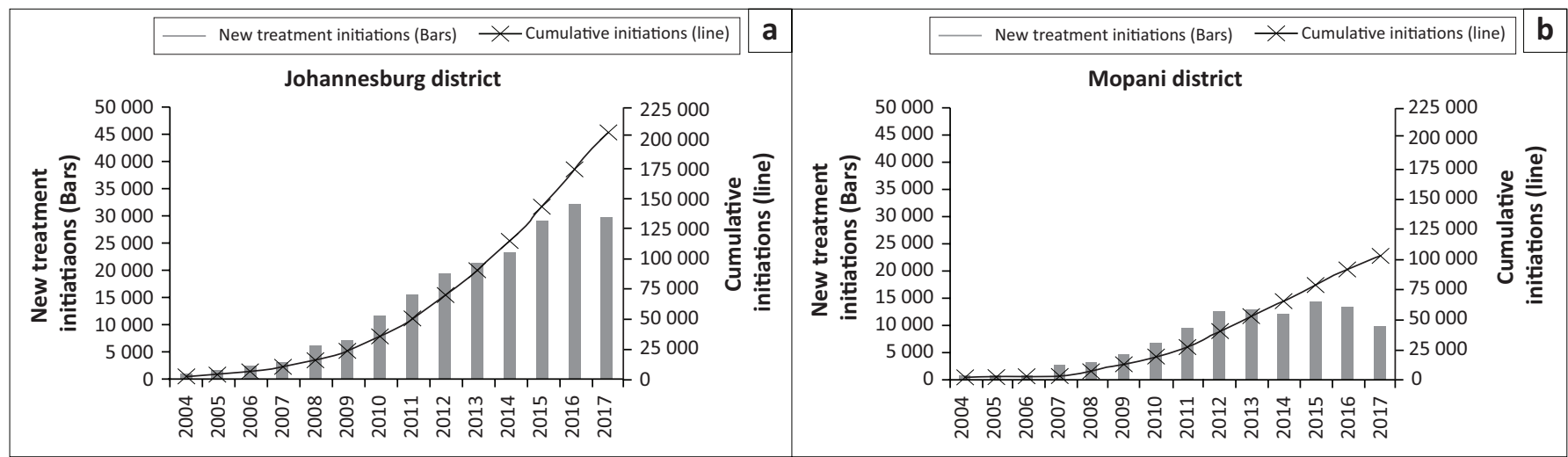

FIGURE 1: Antiretroviral therapy initiations over time among adult clients newly initiating treatment in (a) Johannesburg district and (b) Mopani district. 


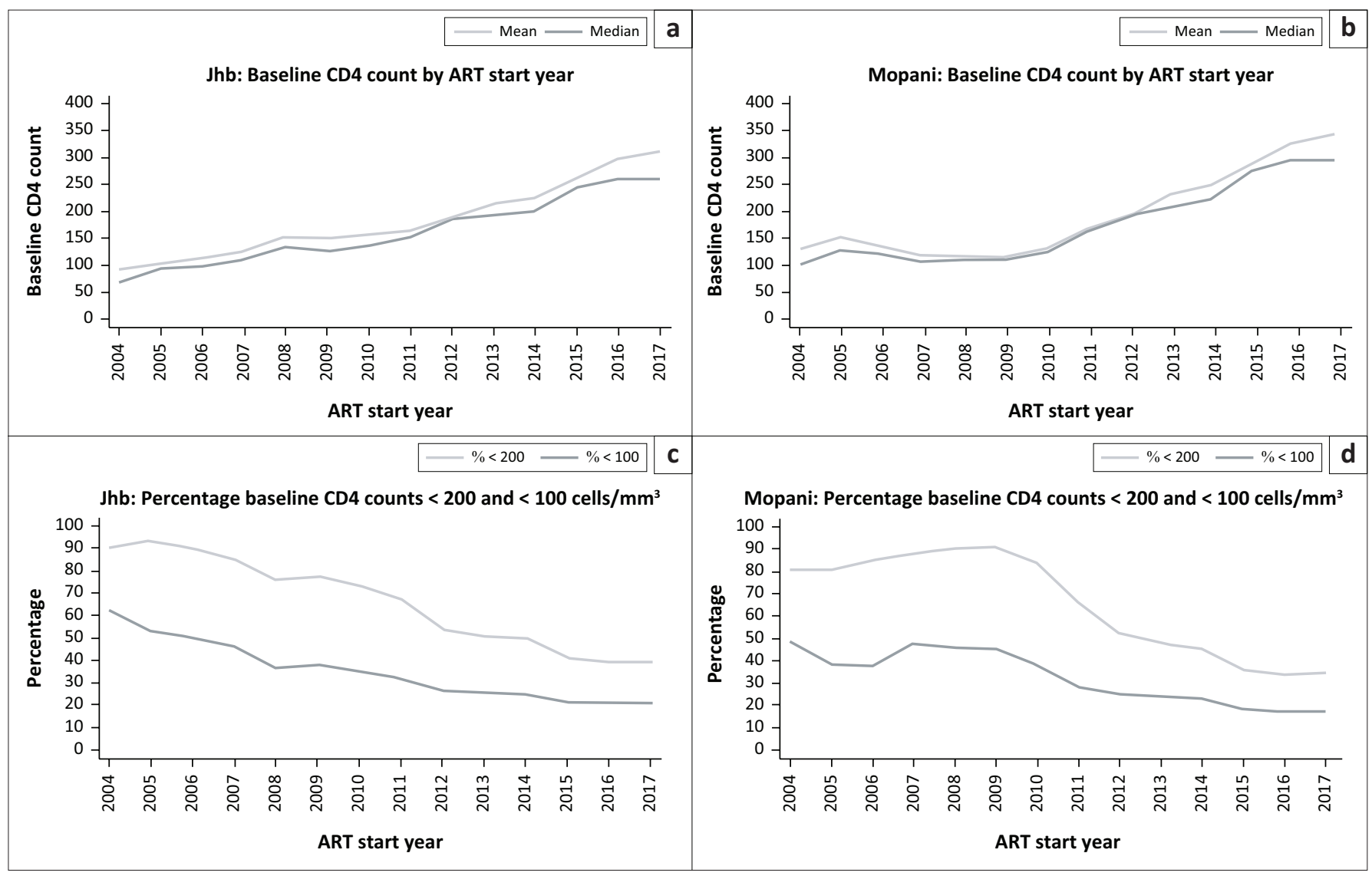

ART, antiretroviral therapy; Jhb, Johannesburg district.

FIGURE 2: Mean and median baseline CD4 count over time and percentage baseline CD4 counts $<200$ and $<100$ cells $/ \mathrm{mm}^{3}$ in Johannesburg district (a and c) and Mopani district ( $b$ and $d)$.

trend, with a consistent increase only being evident from 2009. Although the proportion of baseline CD4 counts $<200$ cells $/ \mathrm{mm}^{3}$ has decreased over time, particularly from 2009 , there has been no decrease in the last 2 years, with percentage counts $<200$ cells $/ \mathrm{mm}^{3}$ remaining at $\pm 40 \%$ in Johannesburg and $\pm 35 \%$ in Mopani (Figure $2 \mathrm{c}$ and $\mathrm{d}$ ).

\section{Mortality survival analysis}

Mortality was significantly higher among clients who initiated ART with CD4 counts $<200$ cells $/ \mathrm{mm}^{3}$ compared to those with higher baseline CD4 counts, with 5-year death rates of $6 \%, 2 \%$ and $1 \%$ among clients with CD4 counts $<200,200-349$ and $\geq 350$ cells $/ \mathrm{mm}^{3}$, respectively, in Johannesburg and $23 \%, 7 \%$ and $5 \%$, respectively, for the same CD4 counts in Mopani ( $p<0.001$ for both districts) (Figure $3 a$ and $b$ ). Early deaths immediately after ART initiation among clients with baseline CD $4<200$ cells $/ \mathrm{mm}^{3}$ are clearly evident. Even in recent years (2016 and 2017), clients with baseline CD $4<200$ cells $/ \mathrm{mm}^{3}$ had significantly higher mortality than those with higher CD4 counts (losses of $2.4 \%$ and $0.4 \%$ in Johannesburg and $9 \%$ and $2 \%$ in Mopani among clients with CD4 counts $<200$ and $\geq 200$ cells $/ \mathrm{mm}^{3}$, respectively ( $p<0.001$ for both districts)). Among clients with baseline CD4 $<200$ cells $/ \mathrm{mm}^{3}$, mortality was lower among those who initiated ART in recent years compared to those who initiated treatment in earlier years of the ART programme ( $p<0.001$ for both Johannesburg and Mopani)
(Figure $3 \mathrm{c}$ and $\mathrm{d}$ ). When ART initiation years were grouped according to timing of drug changes in the South African guidelines, clients with baseline CD $<200$ cells $/ \mathrm{mm}^{3}$ who initiated treatment in years when stavudine was in use had the highest mortality in both districts, with 5-year losses of $13 \%$ in Johannesburg and $48 \%$ in Mopani (Figure 3e and f). In both districts, clients who initiated treatment after tenofovir was introduced had lower mortality rates (5-year losses of $8 \%$ and $25 \%$, respectively) and deaths were even lower after the introduction of an FDC (5-year losses of $4 \%$ and $17 \%$, respectively).

\section{Characteristics and outcomes of clients initiating antiretroviral therapy at CD4 $<200$ cells $/ \mathrm{mm}^{3}$}

Compared to clients with baseline CD4 counts $\geq 200$ cells $/ \mathrm{mm}^{3}$, clients who initiated ART in 2017 with low baseline CD4 counts were more likely to be men and to initiate treatment at older ages $(p<0.001)$ (Table 2$)$. Clients with low baseline CD4 in both districts were more likely to initiate ART at a hospital compared to those starting ART with higher CD4 counts $(p<0.001)$. This correlates with findings of more advanced clinical stage in clients with low baseline CD4 $(p<0.001)$. Among women aged 15-50 years, a significantly lower percentage of clients with CD4 < 200 were pregnant during ART initiation compared to women with higher baseline counts in both districts $(p<0.001)$. 


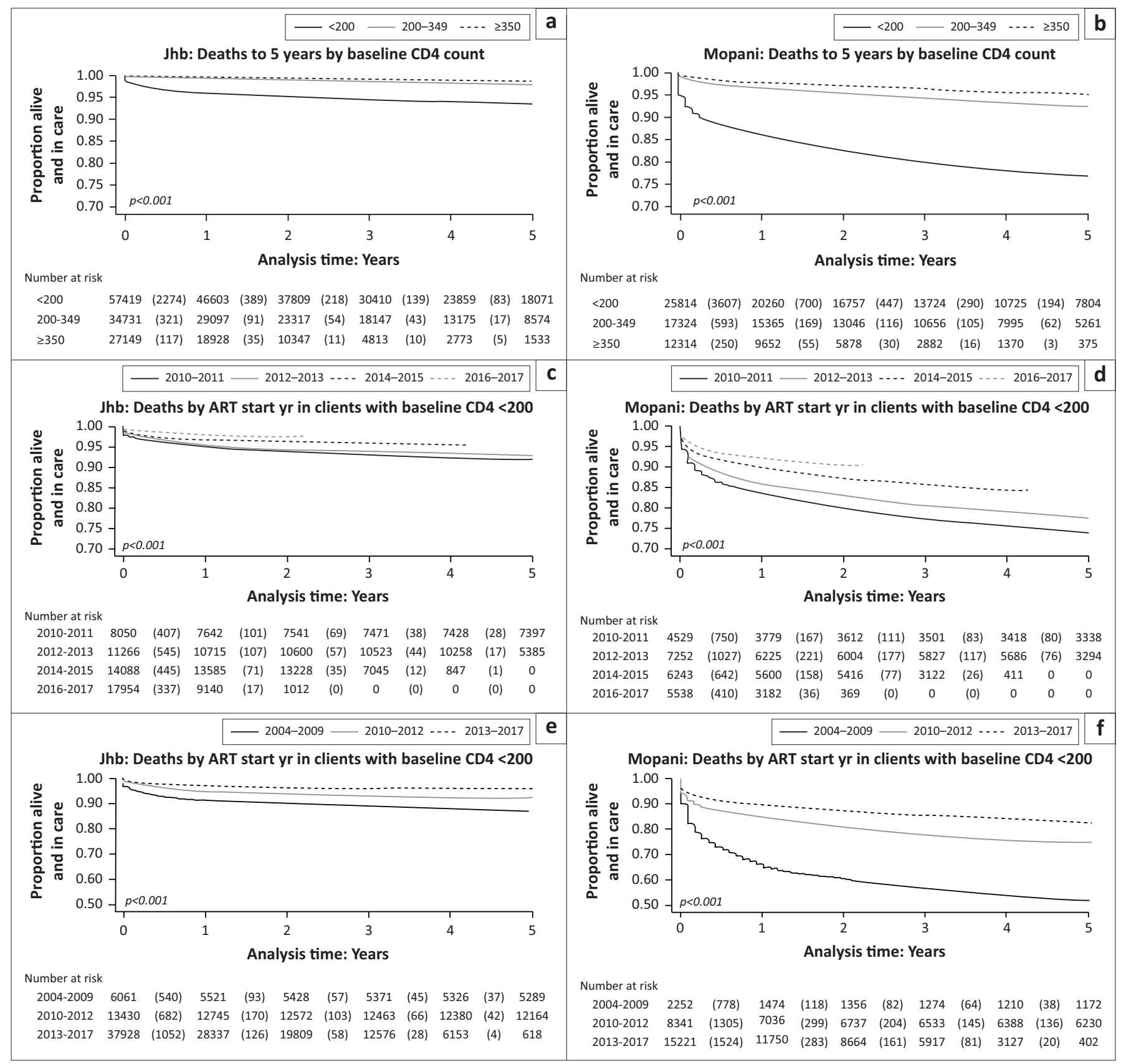

$p=$ Peto-Peto test for equality of survivor functions. ART, antiretroviral therapy; Jhb, Johannesburg district.

FIGURE 3: Kaplan-Meier survival curves of deaths to 5 years by baseline CD4 count in (a) Johannesburg and (b) Mopani. Deaths by year of antiretroviral therapy initiation among clients with baseline CD4 counts $<200$ cells $/ \mathrm{mm}^{3}$ in (c) Johannesburg and (d) Mopani. Deaths by year of antiretroviral therapy initiation among clients with baseline CD4 counts < 200 cells $/ \mathrm{mm}^{3}$ where years have been grouped according to the timing of drug changes in the South African guidelines in (e) Johannesburg and (f) Mopani (2004-2009: single formulation regimens including stavudine; 2010-2012: single formulation regimens including tenofovir; 2013-2017: fixed-dose combination).

Delivery of CPT at treatment initiation in 2017 was poor in Johannesburg and Mopani, only $23 \%$ and $26 \%$ of clients with baseline CD4 counts $<200$ cells $/ \mathrm{mm}^{3}$ are documented as having received $\mathrm{CPT}$, respectively (Table 2 ). Nevertheless, as expected, significantly more clients with low CD4 received CPT compared to clients with CD4 counts $>200$ in both districts $(p<0.001)$ in line with national guidelines. ${ }^{9}$ In the last 5 years (2013-2017), delivery of CPT to clients initiating ART with baseline CD4 counts $<200$ cells $/ \mathrm{mm}^{3}$ has declined in both Johannesburg and Mopani districts (Figure 4). Furthermore, a consistently higher proportion of clients presenting with advanced disease (WHO stage III or IV) received CPT compared to those presenting with WHO stage I or II disease across all 5 years.

Among clients initiating ART at primary care clinics in 2017, mortality was significantly higher and viral suppression was significantly lower among clients with baseline CD4 counts $<200$ cells $/ \mathrm{mm}^{3}$ compared to those with higher baseline counts $(p<0.001)$, with similar findings evident in hospitals (Table 2). The high mortality in Mopani hospitals was largely from a single facility with 16 deaths, although the increased mortality in clients with 
TABLE 2: Characteristics, care and outcomes of adult clients initiating antiretroviral therapy in 2017 by baseline CD4 count.

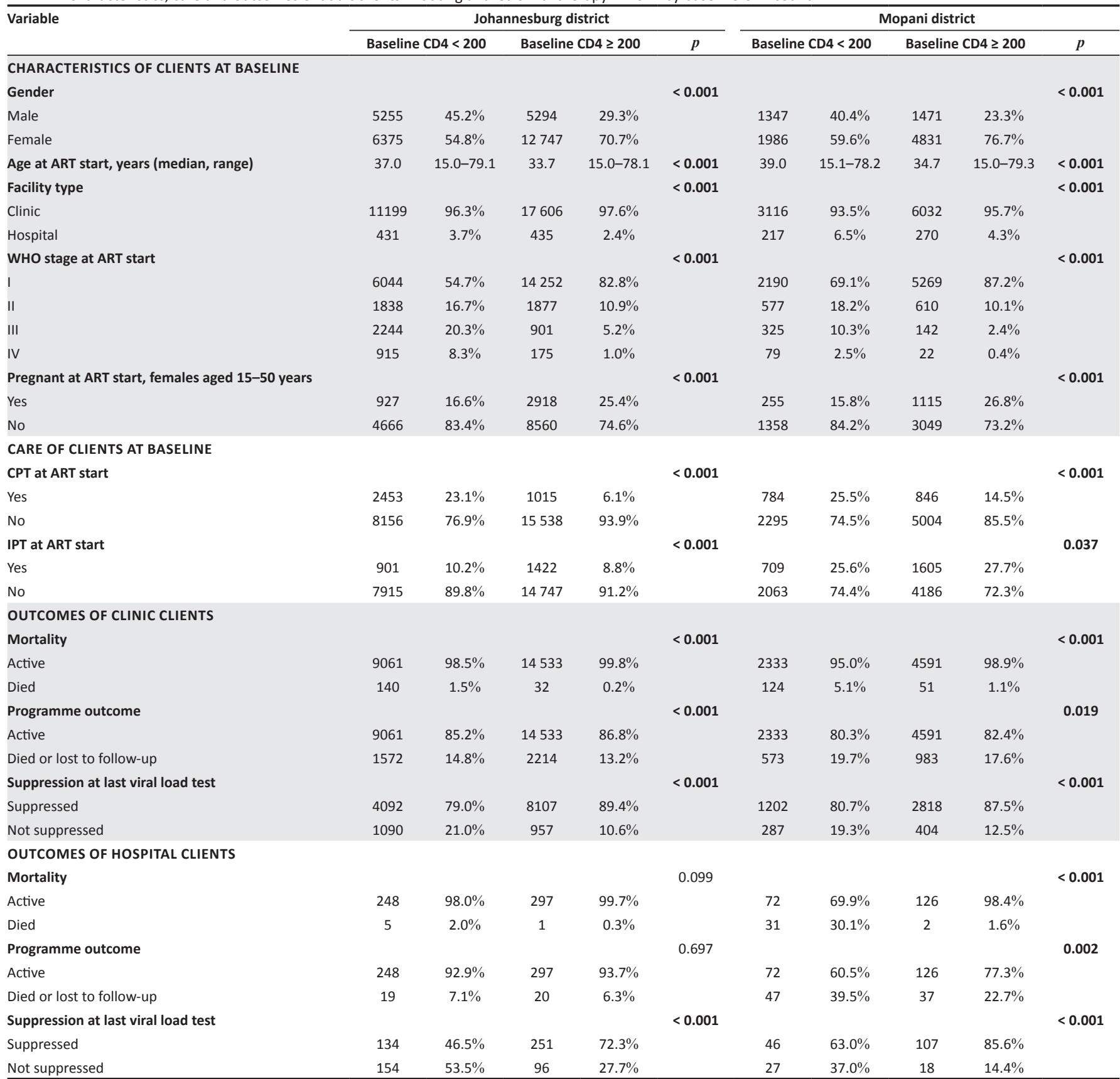

ART, antiretroviral therapy; CPT, cotrimoxazole preventive therapy; IPT, isoniazid preventive therapy; WHO, World Health Organization.

Data are $n(\%)$ unless otherwise indicated. Total value differs between variables because of missing data.

Statistically significant differences are shown in bold.

low CD4 counts in Mopani hospitals remained significant even when this hospital was removed from the analysis $(p<0.001)$.

\section{Discussion}

This study of routine TIER.Net data demonstrates an increase in mean and median baseline CD4 counts over time, in line with South African guidelines that have repeatedly raised the CD4 cut-off for ART initiation ${ }^{5,8,9,10}$ and in agreement with previous findings in South Africa and other countries. ${ }^{2,16,24,25,26}$ However, the improvement in these population measures is masking a high-risk group of clients with low CD4 counts who only initiate treatment once they have advanced HIV disease. Although the proportion of clients initiating ART with CD4 counts $<100$ and $<200$ cell $/ \mathrm{mm}^{3}$ declined in the initial years of the ART programme, as has been previously demonstrated from 2001 to $2012{ }^{12}$ there has been little change in recent years, with the proportion of clients with low baseline CD4 counts remaining concerningly high. This is unexpected in the context of UTT, but it confirms findings from a recent South African study of laboratory data which also noted little change in the proportion of adult clients initiating ART with CD4 counts $<200$ cells $/ \mathrm{mm}^{3}$ between 2012 and 2016, ranging from $32.9 \%$ to $34.8 \%$ nationally. ${ }^{27}$ This is also a challenge in other low- and middle-income 


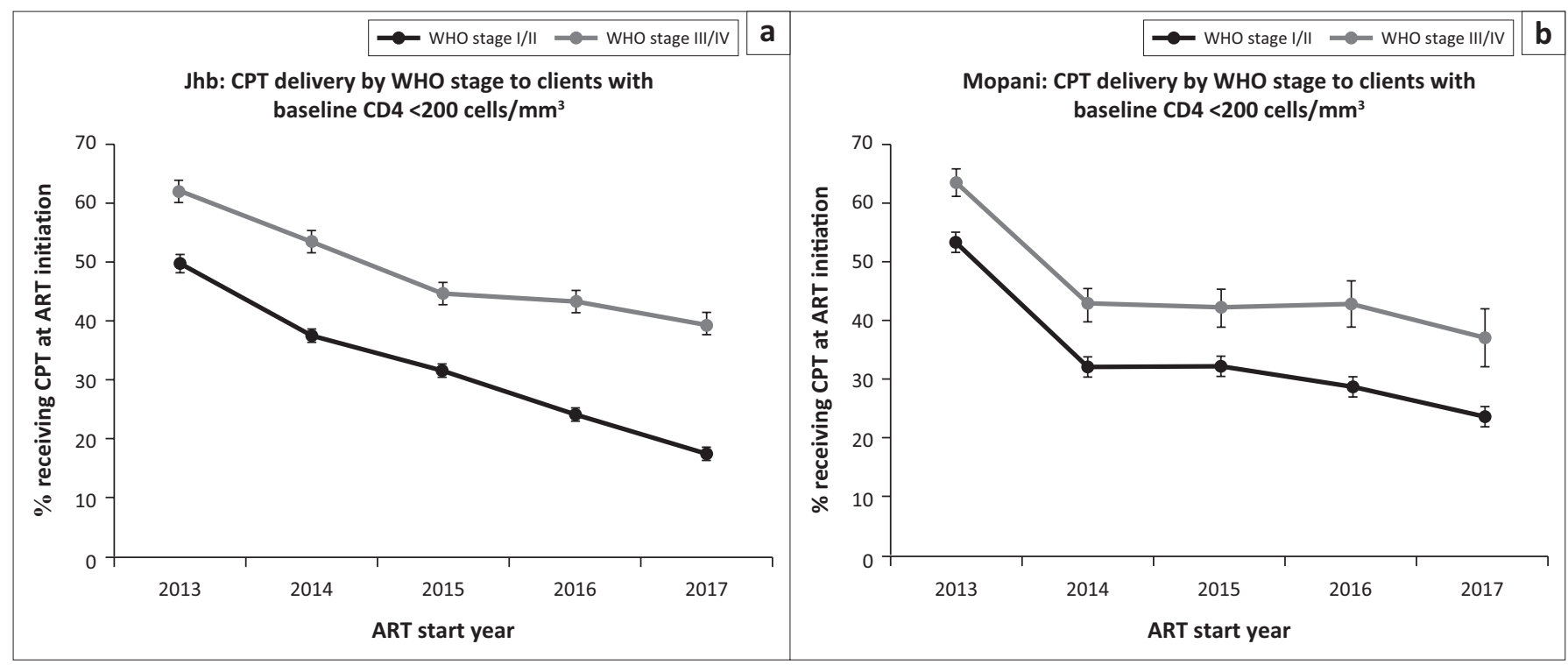

ART, antiretroviral therapy; CPT, cotrimoxazole preventive therapy; Jhb, Johannesburg district; WHO, World Health Organization.

FIGURE 4: Delivery of cotrimoxazole preventive therapy over time to clients with baseline CD4 counts $<200$ cells $/ \mathrm{mm}^{3}$ by clinical stage in (a) Johannesburg district and (b) Mopani district.

countries, with over $30 \%$ of clients initiating treatment with CD4 counts $<200$ cells $/ \mathrm{mm}^{3}$ despite generally widespread availability of ART. ${ }^{24,25}$ These clients, who may either be ARTnaïve or may have previously defaulted from the ART programme, represent a considerable burden of increased medical costs, risk of transmission and HIV morbidity. ${ }^{27}$ Interventions to address HIV incidence as well as barriers to entering care are essential.

Mortality was found to be significantly higher in clients with baseline CD 4 counts $<200$ cells $/ \mathrm{mm}^{3}$ compared to those with higher CD4 counts, as has been well established in South Africa and other settings. ${ }^{3,16,17,28}$ Interestingly, it has been shown that standardised mortality rates which take background mortality into account are similar for all CD4 strata by 4 years after ART initiation, suggesting that baseline immunological status impacts mortality primarily at shorter durations of ART. $^{2}$ It is specifically at these early time periods after ART initiation that there is a notably high mortality rate, as has been demonstrated in this study, specifically among clients with baseline CD4 counts $<200$ cells $/ \mathrm{mm}^{3}$. Other studies in South Africa and sub-Saharan Africa have similarly demonstrated high mortality rates in the first year after starting ART, with up to $26 \%$ of patients dying in the first year of treatment. ${ }^{3,29}$ There is a strong association between early mortality and the degree of immunodeficiency at ART start; therefore, strategies to reduce mortality must address 'up-stream' entry points into the treatment cascade, including earlier diagnosis of HIV and improved longitudinal care pre-ART. ${ }^{29}$

Although clients with low baseline CD4 counts are at increased risk of death, mortality rates have decreased in recent years of the ART programme in this and other studies. ${ }^{2,16,17,26}$ Overall mortality in South Africa has declined in recent years ${ }^{30}$ and the gains in life expectancy have been largely attributed to a decline in HIV-related mortality rates. ${ }^{31}$ This decline can be ascribed to improved accessibility to HIV services with the implementation of nurse-managed care, ${ }^{11}$ as well as improved quality of care because of enhanced drug regimens. This study demonstrated significantly lower mortality among clients with CD 4 counts $<200$ cells $/ \mathrm{mm}^{3}$ who initiated ART in more recent years when an FDC was in use compared to those initiating treatment in previous years, with the highest mortality in years when guidelines recommended the use of stavudine which has a relatively unfavourable toxicity profile. ${ }^{32}$ Antiretroviral therapy using an FDC has been shown in a European study to improve both adherence and quality of life of HIV-infected patients, while maintaining virological and immunologic efficacy. ${ }^{33}$ In general, the simplification of ART with an FDC is associated with improved adherence because of decreased pill burden, reduced risk of resistance owing to the inability of patients to take partial regimens, reduced risk of treatment or prescription errors and lower risk of hospitalisation, ${ }^{34,35}$ supporting the assertion that FDCs may contribute to reduced mortality rates. However, in the context of overall ART programme performance, it is important to note that LTFU appears to be increasing in more recent years, possibly because of the expansion of treatment programmes in the absence of sufficient resources. ${ }^{26,36}$ It is important that overall programme performance is monitored in order to minimise LTFU and the knock-on effect that this could have on mortality.

To improve outcomes of the HIV programme, interventions should focus on clients most likely to present late for HIV care, including, as expected, clients with advanced clinical stage of HIV disease and those in hospitals. Interventions such as community-based strategies or home-based HIV testing should also target men, ${ }^{37,38}$ in agreement with previous studies in South Africa and other low- and middle-income countries which demonstrate late presentation of men for both HIV diagnosis and treatment. ${ }^{39,40,41,42,43}$ This delayed health seeking may contribute to the growing gap between male and female life expectancy, which has doubled from 
2003 to $2011 .^{44}$ Reasons for the disparity are likely to include reluctance of men to seek HIV care because of attitudinal barriers, HIV stigma, perceptions of masculinity and cultural practices, ${ }^{45,46}$ as well as the scale-up of prevention of motherto-child transmission (PMTCT) services, ${ }^{47}$ which have increasingly engaged women in care. This study found that a higher proportion of pregnant women aged 15-50 years had baseline CD4 counts $\geq 200$ cells $/ \mathrm{mm}^{3}$ compared to women who were not pregnant during ART initiation, suggesting that PMTCT services play a role in linking women to timely HIV treatment. This is supported by findings of an association between PMTCT services and higher cohort median CD4 count, as well as reduced risk of ART initiation with advanced disease. ${ }^{41,42,48}$ In addition, late presentation for ART initiation was found to be linked with older age in this study. Mixed findings regarding the association between age and late presentation for care have been reported in the literature, with one study finding no significant association, ${ }^{39}$ others finding a decreased risk of late presentation for HIV care in older clients ${ }^{41,42}$ and yet others demonstrating an increased risk of initiating ART with low CD4 in older clients..$^{25,40}$ The finding of this study that older age is linked to late presentation for care is supported by a recent study of South Africans aged over 50 years who reported seeking HIV testing only once they were symptomatic and referred by a provider or if a partner was diagnosed as infected..$^{49}$ Furthermore, older men in sub-Saharan Africa have been found to be less aware of and knowledgeable about HIV prevention compared to younger men, with increased risk behaviours in some settings..$^{50}$ Educational initiatives and HIV testing strategies that focus on men and the older population are thus required.

An additional intervention to improve outcomes of the HIV programme is delivery of $\mathrm{CPT}$ to high-risk clients presenting for HIV care with low baseline CD4 counts, as recommended by the WHO. ${ }^{51}$ It has been well established that CPT significantly reduces mortality in clients with low baseline CD4 counts, ${ }^{52,53}$ and it is therefore concerning that delivery of this intervention appears to be declining over time, possibly reflecting competing demands on healthcare providers as the ART programme expands. Interestingly, a consistently higher proportion of clients with WHO stage III or IV disease received CPT compared to clients presenting with WHO stage I or II disease, indicating that healthcare providers are more likely to give CPT to clients who appear ill. This is concerning, as clients with immunosuppression who require CPT may not present with advanced disease, as seen in this and other studies, ${ }^{54}$ and delivery of CPT may therefore be missed in these clients. This is likely exacerbated in the era of UTT, as baseline CD4 counts which would alert healthcare providers to the need for $\mathrm{CPT}$ are not required at the time of ART initiation; delivery of $\mathrm{CPT}$ therefore relies on the healthcare provider later checking the CD4 results and subsequently initiating CPT if required, increasing the chance that CPT may be overlooked. Interventions to increase awareness of the importance of baseline CD4 testing and delivery of CPT to clients with low baseline CD4 counts and/or advanced clinical disease are warranted.

The urban and rural districts analysed in this study had comparable findings in terms of overall trends in population CD4 counts, the proportion of clients initiating ART with CD4 $<200$ cells $/ \mathrm{mm}^{3}$ in 2017 and characteristics of clients with low baseline CD4 counts. However, mortality was markedly higher in rural Mopani than in Johannesburg. This highlights the inferior quality of care in the rural district, likely because of poor access to doctors as has been previously described in rural settings, as well as the deficit in specialist medical care in rural provinces of South Africa. ${ }^{55,56,57}$ In addition, characteristics of rural settings, such as lower levels of formal education, are also known to be associated with higher mortality. ${ }^{58}$ While urban settings need to be aware of the rate of programme expansion owing to the increased risk of attrition associated with rapid expansion of ART services, ${ }^{36}$ efforts in rural settings need to focus on quality of care, perhaps by employing mobile units that are staffed by doctors or by providing training for primary healthcare staff.

This study demonstrated the rich source of data available in TIER.Net. The analysis was performed using data spanning over a decade during which there were substantial guideline changes in the ART programme, producing a robust and realistic analysis. On the other hand, this study has a number of limitations. Firstly, TIER.Net was introduced in South Africa in 2010, necessitating the back-capture of data from the ART programme prior to this time. There may have been challenges with the quality of the back-captured data, which may have led to an underestimation of the absolute numbers of clients on ART, including those who died, although we believe that the proportions are representative. Secondly, not all clients in TIER.Net could be included in the analysis because of missing baseline CD4 counts. Thirdly, the study was not designed to follow up clients who were LTFU from the ART programme and it is therefore unclear how many of these clients died. The Kaplan-Meier analyses may therefore underestimate mortality. Finally, although these data are representative of urban and rural areas in South Africa, they should be generalised to other settings with caution, particularly because only two districts were included in the analysis.

\section{Conclusion}

In conclusion, this study of routine programme data demonstrates rapid expansion of South Africa's adult ART programme since 2004. Although median CD4 count has increased over time, this population measure is masking a high-risk group of clients who present late for HIV care with low baseline CD4 counts. Despite improvements in mortality over time, these clients are still at risk of increased mortality, particularly in rural settings. Therefore, targeted interventions are urgently warranted to improve early engagement in care and clinical management, with a specific focus on men, older clients and those presenting at hospitals. Ongoing monitoring 
of the routine programme coupled with targeted interventions will ensure continued improvements in the outcomes of these high-risk individuals.

\section{Acknowledgement}

\section{Competing interest}

The authors have declared that no competing interests exist.

\section{Author contributions}

R.R.L., K.R. and R.P.H.P. conducted the data analysis. M.M., H.E.S. and J.A.M. supported the data collection process. R.R.L. wrote the manuscript. All authors provided in-depth comments and input on all versions of the manuscript and approved the final version.

\section{Data availability statement}

Data are available from the corresponding author upon request.

\section{Funding}

This study is made possible by the generous support of the American people through the US President's Emergency Plan for AIDS Relief (PEPFAR) through the United States Agency for International Development (USAID) under Cooperative Agreement number AID-674-A-12-00015, entitled 'Systems Strengthening for Better HIV/TB Patient Outcomes', and Cooperative Agreement number 72067418CA00023 for the Accelerating Program Achievements to Control the Epidemic (APACE) Activity in South Africa to the Anova Health Institute.

\section{Disclaimer}

The contents presented in this article are the responsibility of Anova Health Institute and do not necessarily reflect the views of USAID or the United States Government. The funders had no role in the study design, data collection and analysis, decision to publish or preparation of the manuscript.

\section{References}

1. Joint United Nations Programme on HIV/AIDS. Country: South Africa [homepage on the Internet]. c2018 [cited 2018 Oct 10]. Available from: http://www.unaids. org/en/regionscountries/countries/southafrica/.

2. Cornell M, Johnson LF, Wood R, et al. Twelve-year mortality in adults initiating antiretroviral therapy in South Africa. J Int AIDS Soc. 2017;20(1):21902. https:// doi.org/10.7448/IAS.20.1.21902

3. Johnson LF, Mossong J, Dorrington RE, et al. Life expectancies of South African adults starting antiretroviral treatment: Collaborative analysis of cohort studies. PLoS Med. 2013;10(4):e1001418. https://doi.org/10.1371/journal.pmed.1001418

4. United Nations. Resolution adopted by the General Assembly on 25 September 2015 - 70/1. Transforming our world: The 2030 agenda for sustainable development. New York: UN; 2015.

5. National Department of Health of South Africa. National antiretroviral treatment guidelines. Pretoria: NDoH; 2004.

6. National Department of Health of South Africa. Clinical guidelines for the management of HIV \& AIDS in adults and adolescents. Pretoria: NDoH; 2010.

7. National Department of Health of South Africa. The South African antiretroviral treatment guidelines. Pretoria: $\mathrm{NDoH} ; 2013$.

8. National Department of Health of South Africa. Implementation of the universal test and treat strategy for HIV positive patients and differentiated care for stable patients (circular). Pretoria: NDoH; 2016.
9. National Department of Health of South Africa. National consolidated guidelines for the prevention of mother-to-child transmission of HIV (PMTCT) and the management of HIV in children, adolescents and adults. Pretoria: NDoH; December 2014

10. South African Government. Statement on the meeting of the South African National AIDS Council [homepage on the Internet]. 2011 [cited 2018 Oct 10]. Available from: https://www.gov.za/statement-meeting-south-african-nationalaids-council-sanac.

11. National Department of Health of South Africa. HIV \& AIDS and STI strategic plan for South Africa 2007-2011. Pretoria: NDoH; 2007.

12. Osler M, Hilderbrand K, Hennessey C, et al. A three-tier framework for monitoring antiretroviral therapy in high HIV burden settings. J Int AIDS Soc. 2014;17:18908. https://doi.org/10.7448/IAS.17.1.18908

13. Meintjes G, Kerkhoff AD, Burton R, et al. HIV-related medical admissions to a South African district hospital remain frequent despite effective antiretroviral therapy scale-up. Medicine (Baltimore). 2015;94(50):e2269. https://doi.org/ 10.1097/MD.0000000000002269

14. World Health Organization. South Africa - HIV country profile: 2017 [homepage on the Internet]. 2019 [cited 2019 Jan 15]. Available from: http://cfs.hivci.org/ country-factsheet.html.

15. Lewden C, Drabo YJ, Zannou DM, et al. Disease patterns and causes of death of hospitalized HIV-positive adults in West Africa: A multicountry survey in the antiretroviral treatment era. J Int AIDS Soc. 2014;17(1):18797. https://doi. org/10.7448/IAS.17.1.18797

16. Nsanzimana $S$, Remera E, Kanters $S$, et al. Life expectancy among HIV-positive patients in Rwanda: A retrospective observational cohort study. Lancet Glob Health. 2015;3(3):e169-177. https://doi.org/10.1016/S2214-109X(14)70364-X

17. Mills EJ, Bakanda C, Birungi J, et al. Life expectancy of persons receiving combination antiretroviral therapy in low-income countries: A cohort analysis from Uganda. Ann Intern Med. 2011;155(4):209-216. https://doi.org/10.7326/ 0003-4819-155-4-201108160-00358

18. Luma HN, Jua P, Donfack OT, et al. Late presentation to HIV/AIDS care at the Douala general hospital, Cameroon: Its associated factors, and consequences. BMC Infect Dis. 2018;18(1):298. https://doi.org/10.1186/s12879-018-3204-8

19. McCreesh N, Andrianakis I, Nsubuga RN, et al. Improving ART programme retention and viral suppression are key to maximising impact of treatment as prevention: A modelling study. BMC Infect Dis. 2017;17(1):557. https://doi. org/10.1186/s12879-017-2664-6

20. Rozhnova G, Anastasaki M, Kretzschmar M. Modelling the dynamics of population viral load measures under HIV treatment as prevention. Infect Dis Model. 2018;3:160-170. https://doi.org/10.1016/j.idm.2018.09.001

21. Massyn N, Padarath A, Peer N, Day C, editors. District Health Barometer 2016/17. Durban: Health Systems Trust; 2017.

22. National Department of Health of South Africa. National antenatal sentinel HIV \& syphilis survey report 2015. Pretoria: NDoH; 2017.

23. StataCorp LLC. sts test - test equality of survivor functions [homepage on the Internet]. 2018 [cited 2018 Oct 11]. Available from: https://www.stata.com/ manuals13/stststest.pdf.

24. Auld AF, Shiraishi RW, Oboho I, et al. Trends in prevalence of advanced HIV disease at antiretroviral therapy enrollment - 10 countries, 2004-2015. MMWR Morb Mortal Wkly Rep. 2017;66(21):558-563. https://doi.org/10.15585/mmwr. mm6621a3

25. IeDEA and ART Cohort Collaborations, Avila D, Althoff KN, et al. Immunodeficiency at the start of combination antiretroviral therapy in low-, middle-, and highincome countries. J Acquir Immune Defic Syndr. 2014;65(1):e8-16. https://doi. org/10.1097/QAl.0b013e3182a39979

26. Katz IT, Kaplan R, Fitzmaurice G, et al. Treatment guidelines and early loss from care for people living with HIV in Cape Town, South Africa: A retrospective cohort study. PLoS Med. 2017;14(11):e1002434. https://doi.org/10.1371/journal. pmed.1002434

27. Carmona S, Bor J, Nattey C, et al. Persistent high burden of advanced HIV disease among patients seeking care in South Africa's national HIV program: Data from a nationwide laboratory cohort. Clin Infect Dis. 2018;66(suppl_2):S111-S117. https://doi.org/10.1093/cid/ciy045

28. Hogg RS, Yip B, Chan KJ, et al. Rates of disease progression by baseline CD4 cell count and viral load after initiating triple-drug therapy. JAMA. 2001;286(20): 2568-2577. https://doi.org/10.1001/jama.286.20.2568

29. Lawn SD, Harries AD, Anglaret X, Myer L, Wood R. Early mortality among adults accessing antiretroviral treatment programmes in sub-Saharan Africa. AIDS 2008;22(15):1897-1908. https://doi.org/10.1097/QAD.0b013e32830007cd

30. Statistics South Africa. Mortality and causes of death in South Africa, 2016: Findings from death notification. Pretoria: StatsSA; 2018.

31. Bor J, Herbst AJ, Newell ML, Barnighausen T. Increases in adult life expectancy in rural South Africa: Valuing the scale-up of HIV treatment. Science. 2013;339(6122):961-965. https://doi.org/10.1126/science.1230413

32. Gallant JE, Staszewski S, Pozniak AL, et al. Efficacy and safety of tenofovir DF vs stavudine in combination therapy in antiretroviral-naive patients: A 3-year randomized trial. JAMA. 2004;292(2):191-201. https://doi.org/10.1001/jama.292.2.191

33. Airoldi M, Zaccarelli M, Bisi L, et al. One-pill once-a-day HAART: A simplification strategy that improves adherence and quality of life of HIV-infected subjects. Patient Prefer Adherence. 2010;4:115-125. https://doi.org/10.2147/PPA.S10330

34. Llibre JM, Arribas JR, Domingo $P$, et al. Clinical implications of fixed-dose coformulations of antiretrovirals on the outcome of HIV-1 therapy. AIDS. 2011;25(14):1683-1690. https://doi.org/10.1097/QAD.0b013e3283499cd9 
35. Nachega JB, Mugavero MJ, Zeier M, Vitoria M, Gallant JE. Treatment simplification in HIV-infected adults as a strategy to prevent toxicity, improve adherence, quality
of life and decrease healthcare costs. Patient Prefer Adherence. 2011;5:357-367. of life and decrease healthcare costs.
https://doi.org/10.2147/PPA.S22771

36. Grimsrud A, Balkan S, Casas EC, et al. Outcomes of antiretroviral therapy over a 10-year period of expansion: A multicohort analysis of African and Asian HIV programs. J Acquir Immune Defic Syndr. 2014;67(2):e55-66. https://doi. programs. J Acquir Immune Defic
org/10.1097/QAl.0000000000000268

37. Lewis L, Maughan-Brown B, Grobler A, et al. Impact of home-based HIV testing services on progress toward the UNAIDS 90-90-90 targets in a hyperendemic area of South Africa. J Acquir Immune Defic Syndr. 2019;80(2):135-144. https://doi. org/10.1097/QAI.0000000000001900

38. Sharma M, Barnabas RV, Celum C. Community-based strategies to strengthen men's engagement in the HIV care cascade in sub-Saharan Africa. PLoS Med. 2017;14(4):e1002262. https://doi.org/10.1371/journal.pmed.1002262

39. Drain PK, Losina E, Parker G, et al. Risk factors for late-stage HIV disease presentation at initial HIV diagnosis in Durban, South Africa. PLoS One. 2013;8(1):e55305. https://doi.org/10.1371/journal.pone.0055305

40. Fomundam HN, Tesfay AR, Mushipe SA, et al. Prevalence and predictors of late presentation for HIV care in South Africa. S Afr Med J. 2017;107(12):1058-1064. https://doi.org/10.7196/SAMJ.2017.v107i12.12358

41. Geng EH, Hunt PW, Diero LO, et al. Trends in the clinical characteristics of HIV-infected patients initiating antiretroviral therapy in Kenya, Uganda and Tanzania between 2002 and 2009. J Int AIDS Soc. 2011;14(1):46. https://doi.org/10.1186/1758-2652-14-46

42. Lahuerta M, Wu Y, Hoffman S, et al. Advanced HIV disease at entry into HIV care and initiation of antiretroviral therapy during 2006-2011: Findings from four subsaharan African countries. Clin Infect Dis. 2014;58(3):432-441. https://doi. org/10.1093/cid/cit724

43. Ndawinz JD, Chaix B, Koulla-Shiro S, et al. Factors associated with late antiretroviral therapy initiation in Cameroon: A representative multilevel analysis. J Antimicrob Chemother. 2013;68(6):1388-1399. https://doi.org/10.1093/jac/dkt011

44. Bor J, Rosen S, Chimbindi N, et al. Mass HIV treatment and sex disparities in life expectancy: Demographic surveillance in rural South Africa. PLoS Med. 2015;12(11):e1001905; discussion e1001905. https://doi.org/10.1371/journal. pmed.1001905

45. Mambanga P, Sirwali RN, Tshitangano T. Factors contributing to men's reluctance to seek HIV counselling and testing at primary health care facilities in Vhembe district of South Africa. Afr J Prim Health Care Fam Med. 2016;8(2):e1-7. https:// doi.org/10.4102/phcfm.v8i2.996

46. Mburu G, Ram M, Siu G, Bitira D, Skovdal M, Holland P. Intersectionality of HIV stigma and masculinity in eastern Uganda: Implications for involving men in HIV programmes. BMC Public Health. 2014;14:1061. https://doi.org/10.1186/14712458-14-1061
47. Sherman GG, Lilian RR, Bhardwaj S, Candy S, Barron P. Laboratory information system data demonstrate successful implementation of the prevention of mother-to-child transmission programme in South Africa. S Afr Med J. 2014:104(3 Suppl 1):235-238, https://doi.org/10.7196/SAMJ. S Afr
7598

48. Nash D, Wu Y, Elul B, Hoos D, El Sadr W, International Center for AIDS Care and Treatment Programs. Program-level and contextual-level determinants of lowmedian CD4+ cell count in cohorts of persons initiating ART in eight sub-Saharan African countries. AIDS. 2011;25(12):1523-1533. https://doi.org/10.1097/QAD. Ob013e32834811b2

49. Schatz E, Knight L. 'I was referred from the other side': Gender and HIV testing among older South Africans living with HIV. PLoS One. 2018;13(4):e0196158 https://doi.org/10.1371/journal.pone.0196158

50. Negin J, Cumming RG. HIV infection in older adults in sub-Saharan Africa: Extrapolating prevalence from existing data. Bull World Health Organ 2010;88(11):847-853. https://doi.org/10.2471/BLT.10.076349

51. World Health Organization. Guidelines for managing advanced HIV disease and rapid initiation of antiretroviral therapy. Geneva: WHO; 2017.

52. Hoffmann CJ, Fielding KL, Charalambous S, et al. Reducing mortality with cotrimoxazole preventive therapy at initiation of antiretroviral therapy in South Africa. AIDS. 2010;24(11):1709-1716. https://doi.org/10.1097/QAD.0b013e328 $33 a c 6 b c$

53. Walker AS, Ford D, Gilks CF, et al. Daily co-trimoxazole prophylaxis in severely immunosuppressed HIV-infected adults in Africa started on combination antiretroviral therapy: An observational analysis of the DART cohort. Lancet. 2010;375(9722):1278-1286. https://doi.org/10.1016/S0140-6736(10)60057-8

54. Hakim J, Musiime V, Szubert AJ, et al. Enhanced prophylaxis plus antiretrovira therapy for advanced HIV infection in Africa. N Engl J Med. 2017;377(3):233-245. https://doi.org/10.1056/NEJMoa1615822

55. Daviaud E, Chopra M. How much is not enough? Human resources requirements for primary health care: A case study from South Africa. Bull World Health Organ. 2008;86(1):46-51. https://doi.org/10.2471/BLT.07.042283

56. Van Rensburg HC. South Africa's protracted struggle for equal distribution and equitable access - still not there. Hum Resour Health. 2014;12:26. https://doi. org/10.1186/1478-4491-12-26

57. Willcox ML, Peersman W, Daou P, et al. Human resources for primary health care in sub-Saharan Africa: Progress or stagnation? Hum Resour Health. 2015;13:76. https://doi.org/10.1186/s12960-015-0073-8

58. Bassett IV, Coleman SM, Giddy J, et al. Barriers to care and 1-year mortality among newly diagnosed HIV-infected people in Durban, South Africa. J Acquir Immune Defic Syndr. 2017;74(4):432-438. https://doi.org/10.1097/QAl.0000000000 001277 